\title{
PENGARUH EDUKASI STIMULASI TUMBUH KEMBANG TERHADAP KEMAMPUAN DETEKSI DINI TUMBUH KEMBANG ANAK USIA 0-5 TAHUN OLEH ORANGTUA
}

\author{
The Influence of Education Stimulation of Growth and Development Towards \\ the Early Detection Ability of Growing in Children Age 0-5 Years by Parents
}

\author{
Siska Nurul Abidah*, Hinda Novianti \\ Universitas Nahdlatul Ulama Surabaya \\ *(siskanurul@unusa.ac.id)
}

\begin{abstract}
ABSTRAK
Stimulasi merupakan salah satu faktor yang mempengaruhi perkembangan anak. Hal ini seringkali oleh sebagian orangtua mengabaikannya akibat ketidaktahuan orangtua tentang cara dan pentingnya memberikan stimulasi anak sejak usia dini. Tujuan penelitian untuk mengetahui pengaruh edukasi stimulasi tumbuh kembang terhadap kemampuan deteksi dini tumbuh kembang anak usia 0-5 tahun oleh orangtua. Penelitian ini merupakan penelitian kuantitatif dengan desain Quasy Eksperiment Desaign dengan rancangan one group pretest postest desaign. Variabel independen adalah edukasi stimulasi tumbuh kembang dan variabel dependen adalah kemampuan orangtua dalam deteksi dini tumbuh kembang anak usia 0-5 tahun. Populasi ibu yang mempunyai anak usia 0-5 tahun. Sampel berjumlah 80 orang dengan cara simple random sampling. Penelitian dilakukan selama 3 bulan yaitu Mei-Juli 2020 di RW 01 dan RW 02 Kelurahan Wonokromo Surabaya. Pengumpulan data berupa kuesioner yang mengacu pada KPSP (Kuesioner Pra Skrining Perkembangan), Uji statistik menggunakan wilcoxon-test. Hasil uji statistik menggunakan uji wilcoxon-test diperoleh hasil nilai signifikan 0,000 ( $p$-value < 0.05 ) artinya terdapat pengaruh edukasi stimulasi tumbuh kembang terhadap kemampuan deteksi dini tumbuh kembang anak usia 0-5 tahun oleh orangtua. Pemberian edukasi stimulasi tumbuh kembang anak oleh orangtua dapat meningkatkan kemampuan orangtua dalam memberikan stimulasi tumbuh kembang sejak dini yang akan berdampak positif seperti meningkatkan perkembangan bahasa dan memori anak, kesiapan anak dalam sekolah dan membantu anak untuk memaksimalkan potensi dalam hidup mereka.
\end{abstract}

Kata Kunci: Tumbuh Kembang; Balita;

\begin{abstract}
Stimulation is one of the factors that influence a child's development. This is often overlooked by some parents due to parents' ignorance of how and the importance of stimulating children from an early age. The purpose of this study was to determine the effect of education on growth stimulation on the ability to detect early growth and development of children aged 0-5 years by parents. This research is a quantitative study with the design of the Quasy Experiment Desaign with the design of one group pretest postest desaign. The independent variable is education of growth stimulation and the dependent variable is the ability of parents in the early detection of growth and development of children aged 0-5 years. Population of mothers who have children aged 0-5 years. Samples amounted to 80 people by means of simple random sampling. The study was conducted for 3 months, Mei-Juni 2020 in RW 01 and RW 02, Wonokromo SubDistrict, Surabaya. Data collection in the form of a questionnaire that refers to KPSP (Pre Development Screening Questionnaire), statistical tests using Wilcoxon-test. Statistical test results using Wilcoxon-test obtained a significant value of 0.000 (p-value <0.05) means that there is an influence of growth and stimulation education on the ability to detect early growth and development of children aged 0-5 years by parents. Parenting education for child growth and development can improve the ability of parents to provide growth and development stimulation from an early age that will have positive impacts such as improving children's language and memory development, children's readiness in school and helping children to maximize their potential in life.
\end{abstract}

Keywords: Growth and Development, Toddler

https://doi.org/10.33860/jik.v14i2.132

(C) 2020 by the authors. Submitted for possible open access publication under the terms and conditions of the Creative Commons Attribution (CC BY SA) license (https://creativecommons.org/licenses/by-sa/4.0/). 


\section{PENDAHULUAN}

Usia dini merupakan periode masa emas (Golden Age), jendela kesempatan dan periode kritis (Critical Period) bagi perkembangan anak. ${ }^{1}$ Stimulasi dini sangat diperlukan oleh anak sebagai rangsangan untuk aspek perkembangan mereka. Hal ini seringkali oleh sebagian orangtua mengabaikannya akibat ketidaktahuan orangtua tentang cara dan pentingnya memberikan stimulasi anak sejak usia dini.

Cakupan pelayanan kesehatan balita dalam deteksi dini tumbuh kembang balita yang mengalami gangguan tumbuh kembang di Indonesia sebanyak 45,7\%. Dalam pelaksanaan program SDIDTK di Jakarta anak usia 0-6 tahun sebanyak 500 diperoleh hasil dari 476 anak yang mendapatkan pelayanan SDIDTK didapatkan 57 anak kelainan tumbuh kembang. ${ }^{2}$

Perkembangan anak dipengaruhi oleh keadaan dengan malnutrisi kronis berat, stimulasi dini yang kurang adekuat, kekurangan yodium dan anemia defisiensi besi. Stimulasi dini adalah rangkaian aktivitas yang bertujuan untuk merangsang anak sehingga terbentuk kemampuan perkembangan dasar tumbuh kembang yang optimal. ${ }^{3}$ Deteksi dini perkembangan perlu dilakukan secara rutin pada anak3 -12 bulan dengan menggunakan KPSP sesuai usia anak. Deteksi dini perkembangan dapat menemukan gangguan pertumbuhan dan perkembangan anaksehingga dapat dilakukan intervensi sedini mungkin. ${ }^{4}$

Pemberian stimulasi diawal atau sejak dini yang diberikan oleh orangtua memberikan dampak positif yaitu perkembangan bahasa dan memori anak, meningkatkan kesiapan anak dalam sekolah dan membantu anak untuk memaksimalkan potensi dalam hidup mereka. ${ }^{5}$ Berdasarkan penelitian Sumiyati tahun 2016, menyatakan bahwa terdapat hubungan yang bermakna antara stimulasi dan perkembangan anak usia 4-5 tahun. ${ }^{6}$ Hal ini didukung oleh penelitian Soedjatmiko tahun 2016 mengatakan terdapat pengaruh pemberian stimulasi orangtua dengan perkembangan anak. $^{7}$

Pemberian edukasi stimulasi tumbuh kembang anak dapat meningkatkan kemampuan orangtua dalam memberikan stimulasi anak sejak usia dini karena ibu adalah pendidik pertama bagi anak-anaknya dari lahir sampai dewasa. Sehingga berdasarkan hal tersebut peneliti tertarik meneliti tentang pengaruh edukasi stimulasi tumbuh kembang terhadap kemampuan deteksi dini tumbuh kembang anak usia 0-5 tahun oleh orangtua.

\section{METODE PENELITIAN}

Penelitian ini merupakan jenis penelitian Quasy Eksperiment Desaign dengan rancangan one group pretest postest desaign. Variabel independen dalam penelitian ini adalah edukasi stimulasi tumbuh kembang dan variabel dependen dalam penelitian ini adalah kemampuan ibu deteksi dini tumbuh kembang anak usia 0-5 tahun. Populasi ibu yang mempunyai anak usia 0-5 tahun. Sampel pada penelitian sebanyak 80 orang dengan cara simple random sampling. Penelitian dilakukan selama 3 bulan yaitu Mei-Juli 2020 di RW 01 dan RW 02 Kelurahan Wonokromo Surabaya.

Edukasi dilakukan oleh peneliti dengan cara memberikan penyuluhan kesehatan berupa ceramah dan video serta diberikan modul. Instrument yang digunakan untuk menilai kemampuan ibu berupa kuesioner yang mengacu pada KPSP berupa pertanyaan dengan 2 pilihan jawaban 'benar' dan "salah" sebanyak 20 item. Pertanyaan terbagi dalam cara stimulasi perkembangan motorik kasar, motorik halus, bahasa, kemandirian dan sosialisasi. Penentuan skor untuk kuesioner menggunakan skala Guttman. Jawaban responden di katakan mampu bila menjawab benar 19-20 dan sebaliknya dikatakan tidak mampu bila menjawab benar $<19$.

Setelah data diperoleh kemudian dilakukan uji statistik menggunakan SPSS yaitu uji wilcoxon-test.

\section{HASIL}

Tabel 1. Menunjukkan hasil sebagian kecil $(11,3 \%)$ responden berusia kurang dari 20 tahun sebanyak 9 orang dan sebagian besar $(62,5 \%)$ berusia $20-35$ tahun sebanyak 50 orang. Tabel 1. Menunjukkan hasil sebagian kecil $(6,3 \%)$ pendidikkan ibu adalah SMP sebanyak 5 orang dan sebagian besar $(52,5 \%)$ pendidikkan ibu adalah SMA/SMK sebanyak 42 orang.

Tabel 1 Menunjukkan hasil sebagian besar (76,3\%) sebelum mendapatkan edukasi masuk dalam kategori tidak mampu sebanyak 61 orang dan sisanya $(23,8 \%)$ masuk kedalam 
kategori mampu sebanyak 19 orang. Tabel 1 Menunjukkan hasil sebagian besar $(93,8 \%)$ setelah mendapatkan edukasi masuk dalam kategori mampu sebanyak 75 orang dan sisanya (6.3\%) masuk kedalam kategori tidak mampu sebanyak 5 orang.

Tabel 1. Distribusi Frekuensi Karakteristik dan Kemampuan Deteksi Dini Responden di RW 01 dan RW 02 Kelurahan Wonokromo

\begin{tabular}{lrc}
\hline Variabel Penelitian & Frekuensi & $\begin{array}{c}\text { Persentase } \\
(\%)\end{array}$ \\
\hline Usia Ibu & & \\
$\quad<20$ Thn & 9 & 11,3 \\
20-35 Thn & 50 & 62,5 \\
$\quad$ 35 Thn & 21 & 26,3 \\
Pendidikan & & \\
$\quad$ SMP & 5 & 6,3 \\
$\quad$ SMA/SMK & 42 & 52,5 \\
$\quad$ PT & 33 & 41,3 \\
Kemampuan Sebelum & & \\
$\quad$ Mampu & 19 & 23,8 \\
$\quad$ Tidak Mampu & 61 & 76,3 \\
Kemampuan Setelah & & \\
$\quad$ Mampu & 75 & 93,8 \\
$\quad$ Tidak Mampu & 5 & 6,3 \\
\hline Su
\end{tabular}

Sumber: data primer, 2020

Tabel 2 Menunjukkan hasil uji menggunakan wilcoxon-test didapatkan nilai signifikansi 0,000 (p-value $<0.05$ ) artinya terdapat pengaruh edukasi stimulasi tumbuh kembang terhadap kemampuan deteksi dini tumbuh kembang anak usia 0-5 tahun oleh orangtua.

Tabel 2. Pengaruh Edukasi Stimulasi Tumbuh Kembang Terhadap Kemampuan Deteksi Dini Tumbuh Kembang Anak Usia 0-5 Tahun Oleh Orangtua Di RW 01 dan RW 02 Kelurahan Wonokromo

\begin{tabular}{|c|c|c|c|c|c|}
\hline \multirow[t]{3}{*}{ Variabel } & \multicolumn{4}{|c|}{ Kemampuan ibu } & \multirow{3}{*}{$\begin{array}{c}\text { Nilai } \\
\mathrm{p}\end{array}$} \\
\hline & \multicolumn{2}{|c|}{ Mampu } & \multicolumn{2}{|c|}{ Tidak Mampu } & \\
\hline & $\mathrm{n}$ & $\%$ & $\mathrm{n}$ & $\%$ & \\
\hline Sebelum & 19 & 24,0 & 61 & 76,0 & \\
\hline Sesudah & 75 & 94,0 & 5 & 6,0 & 0,000 \\
\hline
\end{tabular}

Sumber: data primer, 2020

\section{PEMBAHASAN}

Menurut hasil penelitian menunjukkan hasil sebagian besar kemampuan ibu dalam deteksi dini tumbuh kembang sebelum mendapatkan edukasi masuk dalam kategori tidak mampu sebanyak 61 orang $(76,3 \%)$. Hal ini dipengaruhi oleh usia ibu dan pendidikan ibu. Usia ibu sebagian kecil $(11,3 \%)$ responden berusia kurang dari 20 tahun sebanyak 9 orang. Umur ibu berhubungan dengan pengetahuan, yaitu seiring bertambahnya usia ibu maka pengetahuan ibu juga akan bertambah dan begitu sebaliknya. Selanjutnya, pengetahuan ibu merupakan domain kognitif dalam pembentukan kemampuan ibu dalam melakukan deteksi dini tumbuh kembang anak. $^{8}$

Hasil penelitian menunjukkan bahwa sebagian besar kemampuan ibu melakukan deteksi dini tumbuh kembang anak setelah mendapatkan edukasi masuk dalam kategori mampu sebanyak 75 orang $(93,8 \%)$. Usia ibu sebagian besar masuk kategori usia matang dan sebagian besar berpendidikan menengah atas. Pentingnya pemberian stimulasi dalam mendeteksi dini tumbuh kembang anak salah satunya di pengaruhi oleh faktor umur dan pendidikan. faktor umur dan pendidikan merupakan faktor positif yang dapat mempermudah ibu dalam menerima pengetahuan,inovasi dan informasi baru. ${ }^{9}$ Pada usia matang seseorang juga sudah mulai membina rumah tangga dan belajar menjadi orangtua baru. Sehingga dari pemberian edukasi tentang stimulasi tumbuh kembang akan meningkatkan ibu dan kemampuan ibu dalam deteksi dini tumbuh kembang anak menjadi lebih baik dibandingkan sebelum mendapatkan edukasi. Sebagaimana yang dikemukakan oleh penelitian Fazrin dkk tahun 2018, menyatakan bahwa pengetahuan seseorang dapat diperoleh dari pengalaman, informasi dari guru, orangtua, buku dan media masa. ${ }^{10}$

Berdasarkan hasil penelitian ini menunjukan bahwa kemampuan ibu dalam deteksi dini tumbuh kembang anak semakin baik setelah mendapatkan edukasi. Sehingga hasil penelitian menunjukkan ada pengaruh edukasi stimulasi tumbuh kembang terhadap kemampuan ibu dalam deteksi dini tumbuh kembang anak. Hal ini sesuai dengan pernyataan Sunarsih tahun 2015 yang menyatakan bahwa Peningkatan pengetahuan dan keterampilan seseorang terhadap kesehatan dapat diberikan oleh fasilitator melalui penyampaian informasi melalui media massa seperti media cetak maupun media elektronik. ${ }^{11}$

Pemberian pendidikan kesehatan merupakan strategi yang efektif untuk meningkatkan perilaku kesehatan seseorang dalam hal ini kemampuan deteksi dini tumbuh 
kembang anak. Untuk itu, pengetahuan orangtua yang baik dapat menjadi salah satu faktor penunjang dalam mendukung stimulasi perkembangan anak. Peranan penting orangtua sebagai pengasuh pertama yaitu mengontrol, membimbing dan mendampingi anaknya menuju kedewasaan. ${ }^{12}$ Stimulasi dini adalah Rangkaian aktivitas yang bertujuan untuk merangsang kemampuan perkembangan dasar anak agar terbentuk tumbuh kembang yang optimal. ${ }^{13}$ Kemampuan orangtua dalam melakukan stimulasi harus sesuai tahap perkembangan karena menjadi hal utama jika orangtua menginginkan anaknya untuk tumbuh optimal dan tidak mengalami keterlambatan dalam perkembangannya. ${ }^{14}$

Kemampuan ibu dalam mengasuh anak harus disesuaikan dengan tahap perkembangannya seperti menerapkan stimulasi motorik, stimulasi kognitif, dan mengasah stimulasi berbahasa serta berinteraksi sosial dengan lingkungannya. ${ }^{15}$ Hal ini sesuai dengan penelitian Riska dkk tahun 2017 mengatakan bahwa ibu yang mempunyai kemampuan melakukan stimulasi berpengaruh terhadap perkembangan bayi usia 3-6 bulan. ${ }^{12}$ Selanjutnya hasil penelitian ini juga di dukung oleh penelitian Fazrin dkk tahun 2018, mengatakan bahwa orangtua dan guru mempunyai kesadaran akan pentingnya deteksi dini tumbuh kembang anak lebih baik setelah mendapatkan penyuluhan. ${ }^{10}$ Menurut hasil penelitian oleh Lathifa pada tahun 2016 juga menyimpulkan bahwa ada pengaruh pemberian edukasi pada ibu meningkat pemberian stimulasi tumbuh kembang pada anak balita. ${ }^{16}$

Dampak dari peningkatan pengetahuan yaitu seseorang akan berkembang, lebih obyektif, berwawasan luas dan terbuka sehingga akan diterapkan dengan perbuatan yang positif. ${ }^{17}$ Sebagai agen kesehatan pertama, peran seorang ibu sangat penting yaitu memenuhi kebutuhan asah, asuh, dan asih pada anak. Oleh karena itu, setiap ibu yang memiliki anak usia 0-5 tahun memerlukan informasi untuk meningkatkan pengetahuan, sikap dan keterampilan yang tepat serta harus memiliki kepercayaan diri yang tinggi untuk melakukan deteksi dini tumbuh kembang anaknya sesuai tahap perkembangannya. ${ }^{18}$

\section{KESIMPULAN DAN SARAN}

Berdasarkan Hasil Penelitian Terdapat pengaruh edukasi stimulasi tumbuh kembang terhadap kemampuan deteksi dini tumbuh kembang anak usia 0-5 tahun oleh orangtua. Penelitian ini diharapkan dapat meningkatkan sumber pengetahuan yang terkait dengan stimulasi tumbuh kembang dan deteksi dini tumbuh kembang anak serta sebagai sumber informasi dan evidence based untuk mengembangkan penelitian selanjutnya tentang stimulasi tumbuh kembang anak.

\section{UCAPAN TERIMA KASIH}

Ucapan terimakasih penulis sampaikan kepada Kemenristek Dikti dan Universitas Nahdlatul Ulama Surabaya yang telah banyak membantu pada saat penelitian ini.

\section{DAFTAR PUSTAKA}

1. Imron R. Penyuluhan Pentingnya Penimbangan dan Pemantauan Tumbuh Kembang Balita dengan Teknik Stimulasi, Deteksi dan Intervensi Dini Tumbuh Kembang (Sdidtk) Balita di Posyandu Anggrek Simbaringin Desa Sidosari Natar Lampung Selatan. Sakai Sambayan J Pengabdi Kpd Masy. 2018;2(1):21-5.

2. Kementerian Kesehatan R.I. Pelayanan Stimulasi Deteksi Intervensi Dini Tumbuh Kembang Anak. Kementerian Kesehatan Republik Indonesia. 2018.

3. Kementerian Kesehatan Republik Indonesia. Pedoman Pelaksanaan Stimulasi, Deteksi dan Intervensi Dini Tumbuh Kembang Anak. Summ Policymakers. 2016;

4. Entoh C, Noya F, Ramadhan K. Deteksi Perkembangan Anak Usia 3 Bulan - 72 Bulan Menggunakan Kuesioner Pra Skrining Perkembangan (KPSP). Poltekita J Pengabdi Masy [Internet]. 18 Mei 2020;1(1):8-14. Tersedia pada: http://jurnal.poltekkespalu.ac.id/index.php/PJ $\mathrm{PM} /$ article/view/72

5. Yenawati S. Stimulasi Tumbuh Kembang Anak. Psympathic J Ilm Psikol. 2018;3(1):121-30.

6. Sumiyati, Suparmi, Santjaka A, Hapsari W. Stimulasi perkembangan anak usia 4-5 tahun. J Link. 2016;12(1):34-8.

7. Soedjatmiko S. Pentingnya Stimulasi Dini untuk Merangsang Perkembangan Bayi dan Balita Terutama pada Bayi Risiko Tinggi. Sari Pediatr. 2016;8(3):164.

8. Kurniawati A, Hanifah L. Hubungan Pengetahuan Ibu tentang Stimulasi Tumbuh Kembang Balita dengan Perkembangan Balita Usia 12-36 Bulan di Posyandu Kasih Ibu 7 Banyu Urip Klego Boyolali Tahun 2014. J Kebidanan Indones. 2015;3(1):22-6.

9. Nia AD. Faktor Dominan Karakteristik Ibu 
yang Berhubungan dengan Pertumbuhan dan Perkembangan Balita Usia 2-5 Tahun di Wilayah Kerja PUSKESMAS Nanggolo Kota Padang Tahun 2011. keperawatan anak. 2011;2(2):15-20.

10. Fazrin I, Widiana D, Trianti IR, Baba KJ, Amalia NM, Smaut MY. Pendidikan Kesehatan Deteksi Dini Tumbuh Kembang pada Anak di Paud Lab School UNPGRI Kediri Journal of Community Engagement in Health. J Community Engagem Heal. 2018;1(2):6-14.

11. Sunarsih T. Peran Bidan dalam Parenting Education Sebagai Upaya Peningkatan Tumbuh Kembang Anak Usia Dini. SEAJOM Southeast Asia J Midwifery. 2015;1(1):29-38.

12. Riska destina ER dan AT. Kemampuan ibu melakukan stimulasi untuk perkembangan bayi usia 3-6 bulan di wilayah kerja puskesmas puhjarak kabupaten kediri. 2017;6(1):56-65.

13. Maryunani A. Ilmu Kesehatan Anak Dalam Kebidanan. Ilmu Kesehat Anak Dalam Kebidanan Jakarta Trans Info Media. 2010;

14. Muflihah IS. efektifitas pelatihan deteksi dini tumbuh kembang sesuai tahapan usia anak terhadap pengetahuan dan keterampilan ibu dalam menstimulasi tumbuh kembang balita. 2015;XIII(1):5-9.

15. Andriana D. Tumbuh Kembang \& Terapi Bermain Pada Anak. jakarta: Salemba Medika; 2016.

16. Lathifah NS, Andriani T. Pengaruh Penyuluhan Kesehatan Terhadap Pengetahuan Ibu Tentang Stimulasi Perkembangan Balita Usia 3-5 Tahun Di Posyandu Sakura Kelurahan Gunung Mas Teluk Betung Selatan, Lampung Tahun 2016. J Kebidanan. 2018;4(2):90-6.

17. Imelda. Pengetahuan Ibu Tentang Pemberian Stimulasi Dan Perkembangan Anak Pra Sekolah (3-5 Tahun) Di Banda Aceh. Pengetah Ibu Tentang Pemberian Stimulasi Dan Perkemb Anak Pra Sekol (3-5 Tahun) Di Banda Aceh. 2017;8(3):19-23.

18. Fitriani IS, Oktobriariani RR. Stimulasi, Deteksi dan Intervensi Dini Orang Tua terhadap Pencegahan Penyimpangan Pertumbuhan dan Perkembangan Anak Balita. Indones J Heal Sci. 2017;1(1):1. 